resonance diagnostic procedures. Documents of the National Radiolugical Protection Board, 1991.

41 International Commission on Radiological Protection. Lung cancer risk from indoor exposure to radon daughters. ICRP publication 50. Ann ICRP $1987 ; 17$ (No 1).

42 Committee on the Biological Effects of Ionising Radiation. Health risks of radon and other internally deposited alpha emitters (Beir $I V$ ). Washington, DC: National Radiological Commission, 1988.
43 National Radiological Protection Board. Board statement on radon in homes. Documents of the National Radiological Protection Board 1990;1(1).

4 Department of the Environment. The householder's guide to radon. 2nd ed. London: DoE, 1990.

45 Roscoe RJ, Steenland K, Halperin WE. Lung cancer mortality among nonsmoking uranium miners exposed to radon daughters. fAMA 1989;262: 629-33.

46 Bowie C, Bowie SH. Radon and health. Lancet 1991;337:409-13.

\title{
Quality management in the NHS: the doctor's role-II
}

\author{
D M Berwick, A Enthoven, J P Bunker
}

In last week's issue ( $p$ 235) we argued that the introduction of market conditions into the NHS, designed to achieve greater accountability and create incentives for efficiency and improved quality of care, will not alone be sufficient to achieve improvement. ${ }^{\prime}$ Also needed is a sound and effective method by which medical leaders, managers, and practitioners can implement strategies for improvement. In the absence of such a method efforts to reform the financing of medical care and increases in accountability may result in more waste and fear than progress.

We propose that total quality management (TQM), a collection of approaches to quality, efficiency, and leadership that has matured over the past few decades in industries other than health care, can be used effectively within the health care system as a powerful force for improvement. Last week we reviewed basic principles of TQM and suggested how, with appropriate modifications, these principles can apply to the work of medicine; how market forces can increase the motivation for improvements in quality and efficiency; and how TQM can provide a method for acting on that motivation.

In this article we explore the special opportunities that TQM offers to NHS doctors as leaders of a partnership of managers and other health professionals who together share stewardship of health care in Great Britain. For this partnership of doctors and managers to be effective it will be necessary that doctors understand and participate in management decisions and that managers understand and contribute to the formulation of the goals of medical care.

To achieve fundamental improvement in care new skills will be needed by doctors and managers. These include the ability to work in interdisciplinary teams; to understand medical care as a continually changing and updated process; to collect and interpret data on patient needs, satisfaction, and values, as well as outcome; to accept the need for and take advantage of the opportunities presented by new methods for the drafting, revision, and implementation of standardised patient care management plans or protocols; to collect, aggregate, and analyse and interpret data on the processes of care; and to facilitate the exchange of information with patients. Finally, most important of all is the need for leadership among doctors and managers.

\section{Doctor's essential role in total quality management}

If TQM is to succeed in health care, as we think it can, then doctors will have to have a central role in its practice. This applies even more fundamentally to the NHS than to the disaggregated, fee for service American medical economy. Put boldly, the NHS, unlike much of American health care, is, or at least can be, a system, and because of that it has great potential for rational planned action to meet the needs of those it serves. But that systemic property also creates strong and ineluctable bonds among its components, no one of which can act without the participation of all the others.

The doctors of the NHS, specialists and generalists alike, are key parts of that potential system, and its success may rise or fall depending on the willingness of British doctors to learn, accept, and adapt to the new circumstances of work in an integrated system of care. We believe that TQM offers a set of general principles with which the British medical profession can build an NHS of the future that is proud, capable, supported by its constituents, and, indeed, as satisfying to work in as it has been in the past.

To achieve this transformation will require that doctors accept a body of new skills to learn and practise. Though not taught in medical school, these skills are essential for proper work in an interdependent system of care. Indeed, so crucial are these skills to the successful conduct of medicine in the future that we suggest they be classified as the "new clinical skills" of modern, integrated medical care. They belong in the repertoire of the doctor just as much as the "classical clinical skills" that the new system must preserve and support.

\section{"New clinical skills" of quality management \\ The "new clinical skills" are as follows:}

\section{(1) The ability to perceive and work effectively in} interdependencies

Doctors can and should bear ultimate responsibility for much that occurs in clinical patient care. But it is no longer true, if it ever was, that important patient care processes occur mostly in the transactions between one doctor and one patient. Almost all complex care and much of the care that is simple requires faithful, clear, mutually respectful collaboration among workers with many different credentials. In TQM terms most key processes in health care are cross functional.

For cross functional processes to work in the best interests of those served by them the internal dependencies within those processes must be carefully and explicitly cultivated. On assembly lines workers in TQM organisations learn to ask each other such questions as, "What, exactly do you need from me in order to do your work properly?" and "How have I done at meeting your needs?" These internal "customers and suppliers" seek to clarify their mutual needs and constraints so as to serve each other better.

In a TQM hospital it would be customary for surgeons to approach sisters on the wards regularly with the question, for example, "Is there anything I could have done last week that would have made your work easier?" Teams would exist in which people involved in a common process-such as ordering and reporting laboratory test results, or controlling postoperative pain, or the registration of patients for hospital admission-would take the time to meet, to make their processes or work explicit through such techniques as flow diagrams, and to plan specific steps 
toward process improvement. In such teams hierarchy, education, and status would count for little compared with knowledge of the processes and a willingness to contribute ideas.

How would most doctors fare in a culture that self consciously tried to clarify and manage interdependencies like these? No doubt doctors are as ready as others to listen and share ideas, but traditional medical roles and hierarchies of status may place barriers before doctors who wish to attempt better cross functional work. New skills are needed: the skills and willingness to listen across professional boundaries, to remain silent so that others of different status or background as well as one's colleagues can speak, and to realise that the idea of "process" is a great equaliser. In improving processes degrees and rank matter little; what matters are commitment, knowledge, an open mind, and, perhaps, a little humility.

\section{(2) The ability to work in teams}

A corollary of awareness of interdependency is the willingness to work effectively in teams, to share responsibility, and to relinquish absolute professional autonomy in the service of a shared purpose. TQM entails in most mature models the creation and activity of numerous specially formed teams of people who together can understand and experiment with processes in a way that no one person or no one function can. Teamwork takes time. Effective teams in health care will in almost all situations require active participation of doctors and frequently their leadership. Yet many doctors seem uncomfortable with real team activity. Where TQM has been tried in hospitals so far doctors are often not effective on quality improvement teams. They arrive late or not at all to meetings; they dominate when they are present; and they sometimes leap to solutions before the team has done its proper diagnostic work on the process. They do with processes what they would rarely do with patients - assume that they have the answer even before the question has been clearly formulated and data have been collected. If working in teams is an essential new skill in clinical medicine then it belongs in the curriculum and consciousness of medical education at all levels.

\section{(3) The ability to understand work as process}

Work should be understood as a process that is subject to continuous review and improvement as new and better data become available.

Effective management of quality begins with deepening understanding of the actual way in which work is done, and this exploration requires disciplined methods and an open mind. For the doctor in TQM the key question when something goes wrong is not, "Who did this?" but rather, "What is the underlying process of work that contains the likely causal system?" Becoming process minded is harder in medicine than in other industries, largely because so much of the way work is done in medicine has been inherited and not consciously designed.

Note that the term "process" in the TQM context has a more inclusive meaning than is usual in medical contexts. In health care "process" usually refers to clinical care. In TQM it means the way in which work is done, and it refers to work sequences of any type, clinical, non-clinical, or the interface between these two.

An orientation toward understanding processes or work is an important first step toward "driving out fear," one of the central precepts of TQM. The fear to be driven out in medicine is the fear of being made the scapegoat, of appearing to be ignorant, or just of looking foolish (and even, increasingly, of being sued for malpractice). It is a fear that leads to efforts of concealment. When one blames processes and not people it becomes safer to lay bare the relevant facts and for everyone to get to work to improve the process. Angry, accusatory behaviour by doctors who are frustrated by poor results may give those doctors a good deal of self satisfaction at the moment but will be unlikely to result in fundamentally better performance in the long run. On the other hand, seeing work in process terms can easily lead the physician and everyone else to understand that "there, but for the grace of God, go I" and results in the sort of empathetic and collaborative behaviour that fosters improvement. How silly it is to blame people for process flaws.

(4) Skill in collecting, aggregating, analysing, and displaying data on outcomes of care

Quality improvement requires the collection and analysis of data on patient needs, patient satisfaction, and patient values and preferences, as well as data on outcomes. These are types of data with which physicians have had little experience.

There is an important linkage between the measurement of health status outcomes and patient satisfaction, on the one hand, and TQM on the other. Outcomes and satisfaction are results, and any organisation or physician interested in improvement must certainly measure results systematically; otherwise how could it navigate? If TQM becomes the way of the future for the NHS then NHS doctors need to become not just accepting of, but enthusiastic about, measuring the results of care. Furthermore, as no single doctor's experience will be sufficient in volume to permit sound inferences about outcomes, doctors must become generous and skilled in contributing carefully collected data on results to common databases, so that the effects of various approaches can be better understood. The purpose of such aggregated data is not judgment and discipline of individuals, but rather education and improvement for all. In Working for Patients ${ }^{2}$ the government has made a strong commitment to the implementation of computerised medical information systems, and in so doing has set the stage for the collection, analysis, and display of the necessary process and outcome data.

Such measurement and learning is not a small undertaking, but reliable methods are becoming available for routine use. ${ }^{3}$ Adjustment for differences in case mix is perhaps the most difficult statistical problem. While still imperfect, improved and practical methods are now available. ${ }^{+}$The recent introduction of simple methods (including methods of gathering patients' self reports) for the reliable measurement of dimensions of health status - such as physical, role, and social function; mental health; self perceived health; and bodily pain-provide us with powerful new tools for assessing patient outcome. ${ }^{3}$ These functional outcomes should now become as routine and standard as the measurement of physiological variables is today.

\section{(5) Skills in "designing" health care practices}

In the atmosphere of surveillance and apprehension that characterises much of health care, protocols and guidelines for clinical practice have been swept up into a contentious rhetoric. Frustrated payers threaten to use uniform standard practice protocols to judge the quality and efficiency of care givers. Doctors and hospitals resist protocols as "cookbook medicine" that threatens the art and autonomy of medical practice. In this battling a simple fact is often overlooked-namely, that careful artisans often use specific plans to guide them in their own work. Builders use blueprints, chefs use recipes, teachers use lesson plans, artists use sketches; and doctors themselves, perhaps not recognising them as such, have used diagnostic and 


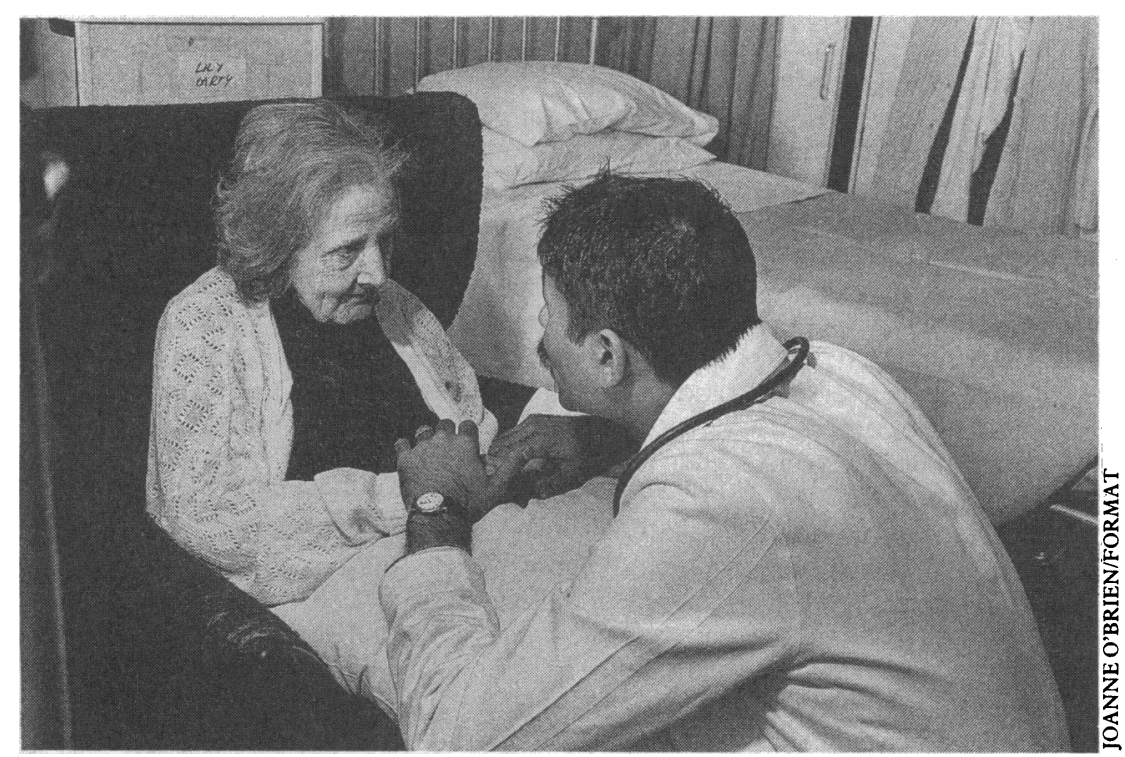

Total quality management for doctors means meeting the needs of those who depend on them

therapeutic routines as "rules of thumb," often handed down from "the chief," for as long as medicine has been practised. ${ }^{67}$

In the improvement of quality specific protocols of action-statements of intended behaviours and practices - can be extremely helpful. Stabilising a procedure is a precondition to improving it. ${ }^{8}$ If a cardiovascular surgeon reinvented the process for cardiopulmonary bypass every time it was to be used operations could not proceed smoothly. A paediatrician who fundamentally reconsiders the right approach to the initial treatment of asthma for every single new routine case would be wasting time.

The threat to doctors from protocols arises not from the idea of protocols, but rather from their potential misuse. Used properly, well considered "standard procedures" can improve quality, reliability, and efficiency without compromise in the pride or authority of those who use them. ${ }^{6}$ Doctors intrigued with TQM will wish to learn methods for drafting, revising, and implementing some standardised patient care management plans, often called algorithms, protocols, or guidelines. ${ }^{10}$ For these doctors such algorithms will serve as blueprints serve builders or as experimental protocols serve researchers. Used in this way care algorithms will not offend the doctors; they will be a tool for learning and improvement. ${ }^{9}$

\section{(6) Skill in collecting, aggregating, analysing, and} displaying data on processes of work

Measuring important variables within processes is often even more difficult than measuring outcomes, but it, too, can be done if people have enough commitment and trust in its importance. "Key process characteristics," those aspects of processes of work that relate most closely to achieving desired results and to satisfying customer needs, are part of the measurement system of any mature quality management organisation. Unaccustomed as health care organisations are to measuring outcome systematically, they are even less familiar with process measurement, and yet without process measurements assessing outcomes is simply an exercise in frustration. It is like measuring football scores without any knowledge of the way the game was played-useful for awarding trophies, perhaps, but useless in achieving improvements.

The process of clinical decision making has, of course, not been neglected. Medical audit and its many variants, the measurement of clinical appropriateness, the setting of standards and guidelines, consensus conferences, and clinical algorithms have been the tocus of a vast American industry that has had virtually no impact on the quality of care, for reasons we discuss below. The process for how medical care is delivered to patients, a process that can have important impact on patient outcome as well as on patient satisfaction, has been largely ignored.

Health care can borrow from other industries simple methods for measuring and displaying the characteristics of the processes of work that it intends to improve. The basic tools of quality improvement include simple graphical methods like flow diagrams, histograms, and run charts, as well as more complicated methods like control charts, that can help anyone with minimal training understand the nature of variation in the system under study. These graphical tools, as well as a positive view of the role of measurement of both outcomes of care and processes of work, should become part of the "clinical" armamentarium of doctors from medical school onward."

\section{(7) Skills in collaborative exchange with patients}

In the TQM approach purpose comes from those served-that is, the customers. All modern practitioners of TQM seek continuous refinement of their ability to know what their customers want and need. They develop and use many ways to find out about those needs and to determine how closely their performance is meeting those needs. Anything produced that does not meet a need is, by definition, waste and poor quality. Efficiency is the ability to meet needs without waste.

This driving core for TQM - meet the needs of those who depend on you-implies a level of dialogue and shared authority that is not customary in medical practice. Patients have become used to a passive role, accepting the advice of doctors without inquiry into their own, special needs. Doctors have become comfortable with assuming that they already know the needs of patients, or can better judge what the patients really want than can the patients themselves. Barry et al have recently suggested that much waste and miscommunication occurs in the gap between unexpressed patient preferences and the misunderstood intents of doctors. " Often, for example, the patient with prostatism is able, with help, to disclose a very different set of relative preferences for, say, operative risks and relief of obstructive symptoms than the doctor may assume. Without sound information on risks, benefits, and preferences the doctor and patient may together make a choice that neither would make with more complete information.

Good doctors often begin encounters with patients with the question, "What can I do for you?" The challenge in TQM is to broaden that question into an organisational and personal way of life, and to ask always not just, "What can I do for you?" but also, after the fact, "How well have I done for you?" Doctors, like all members of the health care team, need training and support to learn to ask these questions, unafraid, in many ways and in many settings.

\section{(8) Skills in working collaboratively with lay managers}

One of the most costly side effects of increasing frustration in modern health care has been the estrangement of doctors from the lay managers. In America the matter approaches damaging levels. Medical staff in hospitals spend an extraordinary amount of their formal and informal time criticising, doubting, and questioning the motives of lay administrators. "They do not understand medicine," say the doctors.

Administrators, in their turn, fret about the doctors, who do not seem to be "controllable," or willing to behave realistically given organisational constraints. Many managers count their week successful if the brushfire arguments between doctors and admini- 
strators have been kept under control. Little energy is left for collaborative improvement.

In the United States, though much less in the United Kingdom, the conflict between medicine and management has taken another turn as a new breed of doctormanager, some with bilateral credentials, has taken form. These often talented and highly qualified people live a complicated life, sometimes doubted by colleagues on both sides, each assuming that the chimera's real loyalty lies with the other. Such a breed of doctormanager seems still to be rare in the United Kingdom.

The conflict is silly and costly, and TQM has little patience for it. The patients and the other customers of health care could hardly care less about the internal feuds and squabbles, It is not unlikely that most patients and other health care customers imagine that doctors in their meetings spend their time and energy trying to figure out how to make care better, and that managers in their meetings do the same. These same customers might be distressed to learn that their money and the time of professionals of both types was often being consumed in tribal rituals of preparation for war.

TQM will not thrive if this gap persists. Care in modern medicine is complicated, and it crosses over and back between clinical and administrative domains without regard to the sensibilities and treaties between doctors and managers. Collaboration is required if processes are to be improved.

The skill base for such collaboration entails considerable knowledge by each party of the work of the other. Both must be willing constantly to reconsider and potentially to change longstanding habits, assumptions, and processes of work. Lay managers must be made welcome in the clinicians' lair, and clinicians must be helped to understand and respect the many sciences of management. For the collaboration to succeed it is equally important that managers know a great deal about the history of medicine in general, and of the NHS in particular. They must acquire a working knowledge of the conditions under which doctors make decisions by regular visits to the wards and clinics. They must understand the high stakes and uncertain scientific base on which many medical decisions must be made; and to do this they must study the systematic methods used to evaluate medical care: cost-benefit analysis, ${ }^{12}$ randomised clinical trials, decision analysis, ${ }^{13}$ and outcomes management, ${ }^{5}$ including risk adjusting methodology. ${ }^{4}$ For them to collaborate effectively with doctors and nurses in the many management decisions that must be made, indeed, to be able to communicate with health professionals, these skills will be essential.

\section{Doctor-managers and consultant leaders}

Joint degree programmes can clearly help in fostering collaboration between managers and health professionals, but the familiarity and respect must extend deeply into both professions, and the solution must not be left to depend on the few who bridge the gap themselves through their own career choices. Doctor-managers, if they are to be effective, face the awesome need to be skilled in both of the areas of their responsibility, and to be recognised as having these skills. It is particularly important that they be recognised as leaders in the practice of medicine, for only then will their colleagues accept their leadership and delegate many of the critically important managerial and administrative decisions that profoundly effect how medicine can be practised. If this sounds like a hopelessly utopian goal, this is one area where there has been considerable success in America. Particularly notable is the Robert Wood Johnson Clinical Scholar Program that provides two or three years of support to young doctors, usually on com- pletion of formal residency training, and which has consistently attracted outstanding applicants. Training of clinical scholars varies at the discretion of the individual but focuses predominantly on medical "conomics, statistics, information sciences, and medical sociology. Graduates of the programme have gone on to accept major positions in medical groups, teaching hospitals, and government.

It will not be enough simply to have a small number of highly trained and talented doctor-managers. Practising general practitioners and consultants will need to have some managerial and quantitative analytical skills. General practitioners, to fulfil their responsibilities as gate keepers and care givers, must understand decision analysis and probability theory. They must be able to take advantage of computerised medical information technology and its access to data relevant to the patient at hand in order to refine the decision whether to refer or to provide care, and if they are going to provide care which treatment will provide the highest probability of the desired outcome. For this to happen it will, of course, be necessary to undergo a level of training not usual in the past, a level of training and expertise perhaps as demanding as that of the specialist consultant.

The consultant leader's need for managerial and quantitative skills are equally great. It is to the clinical leader that we must now turn in meeting the urgent challenge to improve the quality of medical care. It had been hoped that the results of medical audit and consensus conferences and the introduction of clinical guidelines would be adopted by the profession to improve the quality of practice. This has failed to happen, and it is only with clinical leadership that this is now beginning to occur. ${ }^{14}$

The clinical leader must be exactly that, a leader of clinicians, recognised as such by them. He or she must be extremely competent in collaboratively reviewing clinical practices and agreeing on common guidelines according to which clinical decisions will be made. Such a clinical leader must have the managerial and quantitative skills necessary to "manage" the team of colleagues for whom he or she has accepted leadership. This will certainly require additional training and motivation at the outset, but, with time, such quantitative skills should and will become an integral part of clinical and bedside teaching and practice.

\section{Barriers to participation of doctors in managing quality}

At least four important barriers must be overcome if NHS doctors are to acquire and rely on these new clinical skills.

\section{(1) Time}

Being involved with TQM takes time-the time to learn the methods, to listen to patients, to work on teams, to collect data on processes and results, and to teach others. Where will doctors, used to being (and appearing to be) very busy indeed, find the time to join in this effort? The barrier may be even more severe for the general practitioner in a singlehanded practice than for the hospital based consultant as the consultant is physically present in the organisation that can first and most readily employ the techniques of TQM. The NHS will have to solve this problem, creating ways and means for doctors to participate within the constraints of their already busy lives.

\section{(2) Territory}

TQM methods establish control over work processes, thus enabling those doing the work to carry on with a reduced sense of frustration, waste, and helplessness. Paradoxically, this control by people over their own 
work is established only when people are willing to see themselves as bound in unavoidable interdependency with others. For doctors (and others), used to some clarity about whose turf is whose, the initial feelings can be of discomfort and loss. The agenda of TQM demands none the less that barriers between functional areas be broken down so that cross functional processes can become more transparent and, eventually, streamlined.

\section{(3) Tradition}

Medical practice contains habits that will prove dysfunctional in the world of quality management. Many are subtle unspoken rules about who may speak when and to whom, beliefs of where wisdom does and does not reside, and rituals that waste time and diffuse purpose. The rules of interaction in managing quality must be shaped according to three priorities: the increasing of knowledge about the people served, the increasing of knowledge about the processes of work, and the use of scientific methods for improving work. Habits that impede these three objectives will slow the improvement of quality.

The traditions of behaviour are perpetuated through the actions of formal and informal leaders. In the transition to TQM leaders must examine their own behaviours, and change them if required. Do they, themselves, seek and use information about customers and processes? Do they blame people or focus attention on processes instead? Do they produce fear or apprehension in others? Do they, themselves, use statistical methods to interpret data, and do they reserve time for learning, just as they expect others to? Do they place improvement of quality at the top of their own agenda, and, if so, how would others realise this by observing them? Do they rely on exhortation, incentives, and inspection to improve quality, or do they show in their actions that they believe that the missing element when quality fails is usually not motivation but knowledge?

If the capabilities of the NHS are to change through the use of TQM then the change must begin with its leaders, including managers as well as doctors and other health professionals. These changes must surely involve not only the actual NHS apparatus, but also important activities in the prestigious royal colleges which set the norms of behaviour and priority for so much of British medicine.

\section{(4) Trust}

However hopeful TQM may be as a useful approach for increasing the capability of the NHS, only a fool would claim that its promise is certain. It is, all things told, we think, the best bet. No other alternative exists that is on its face value as persuasive, nor that has as consistent and dramatic a track record in other industries. It is a risk worth taking.

But taking that risk will entail a very high degree of consistency of purpose and collaboration among the parties to the NHS. TQM requires learning, experimentation, reliance on others, willingness to be vulnerable, and, above all, leadership. The BMF's editor reminds us, in agreement with "all the quality gurus ... that nothing works without a strong commitment from an organisation's leaders."'s That commitment must be reflected in their time, in their behaviours, in their budgets, and, most of all, in the ways they deal with each other. Without it TQM can have little impact. With it there is little to keep British health care and the NHS from being the example for the world to envy that it has been in the past.

1 Berwick DM, Enthoven A, Bunker JP. Quality management in the NHS: the doctor's role-1. BMF 1992;304:235-9.

2 Secretaries of State for Health, Wales, Northern Ireland, and Scotland. Working for patients. London: HMSO, 1989. (Cmnd 555 .)

3 Tarlov AR, Ware JE, Greenfield S, Nelson EC, Perrin E, Zubkoff M. The medical outcomes study: an application of methods for monitoring the results of medical care. $\mathcal{F} A M A$ 1989;262:925-30.

+ Blumberg MS. Risk adjusting health care outcomes: a methodologic review. Med Care Rev 1986;43:351-96.

5 Ellwood PM. Outcomes management: a technology of patient experience. N Engl F Med 1988;318:1549-56.

6 Berwick DM. Practice guidelines: promise or threat? HMO Practice $1991 ; 5: 174-7$.

7 Eddy DM. Clinical policies and the quality of clinical practice. $N \mathrm{Engl} / \mathrm{Med}$ 1982;307:343-7.

8 Berwick DM. Controlling variation in health care: a consultation from Walter Shewhart. Med Care 1991;29:1212-25.

9 Berwick DM. Commentary: peer review and quality management: are they compatible? Quality Review Bulletin 1990;16:246-51.

10 Margolis CZ. Solving common pediatric problems: an algorithm approach. New York: The Solomon Press, 1988

11 Barry MJ, Mulley AG Jr, Fowler FJ, Wennberg JW. Watchful waiting vs immediate transurethral resection for symptomatic prostatism: the importance of patients' preferences. FAMA 1988;259:3010-7.

12 Bunker JP, Barnes BA, Mosteller F, eds. Costs, risks, and benefits of surgery. New York: Oxford University Press, 1977.

13 Weinstein MC, Fineberg HV, eds. Clinical decision analysis. Philadelphia: W Saunders, 1980.

14 Lomas J, Enkin M, Anderson GM, Hanna WJ, Vayda E, Singer J, et al. Opinion leaders vs audit and feedback to implement practice guidelines: delivery after previous cesarean section. $\mathscr{Y} A M A$ 1991;265:2202-7.

15 Smith R. Medicine's need for kaizen: putting quality first. BMF 1990;301 679-80.

(Accepted 7 fanuary 1992)
What is the rationale behind the recommendation that immunisations with living viruses-for example, for yellow fever and polio-should be given either simultaneously or separated by three weeks?

It is true that the official recommendation in the United Kingdom and the United States is that live vaccines should be given either simultaneously or separated by an interval of three weeks. ${ }^{1}$ There are many data showing that live virus vaccines, when given together with other live virus vaccines and killed bacterial vaccines, produce immune responses and adverse reactions at rates that are no different from those produced when they are administered separately. Examples of combinations for which this has been shown are mumps, measles, and rubella with triple vaccine and oral polio ${ }^{2}$; smallpox, measles, yellow fever, and triple vaccine; varicella and mumps, measles, and rubella; measles, mumps, smallpox, and oral polio; and BCG, diphtheria-tetanus, and oral polio.

Before an immune response is mounted to a live vaccine the organism has to multiply to provide an adequate antigenic stimulus. This does not apply to inactivated vaccines. There is a concern that if a live vaccine was given one to two weeks after another live vaccine the nonspecific components of the immunological response to the first - for example, complement and interferon-would be sufficient to inhibit the second virus, such that no immunity would be produced. In fact there are no data to support this view, and in the case of oral polio vaccine, as the main site of action is the gut, it is unlikely that it would interfere with any of the other live vaccines, all of which are currently given by injection. Until there is positive proof that you can give live virus vaccines at an interval of less than three weeks without loss of immunity you should follow the advice of the Department of Health. - DAvID ELLIMAN, consultant in community child health, London

1 American Academy of Pediatrics. Report of the committee on infectious diseases. Illinois: American Academy of Pediatrics, 1991

2 Deforest A, Long SS, Lischener HW, Girone JAC, Clark JL, Srinivasan R, et al. Simultaneous administration of measles-mumps-rubella vaccine with oral booster doses of diphtheria-tetanus-pertussis and poliovirus vaccines. Pediatrics 1988;81:237-46

3 Galbraith NS, Crosby G, Barnes JM, Fernandes R. Simultaneous immunisation with BCG, diphtheria-tetanus, and oral polio vaccines in children aged 13-14. BMF 1971:i:193-7. 